\title{
Efficiency of tube settler on removal of roagulated particles
}

\author{
Sofyan Al-Dulaimi ${ }^{1, *}$, and Gabriel Racovițeanu ${ }^{1}$ \\ ${ }^{1}$ Technical University of Civil Engineering Bucharest, Dept. of Water Engineering, Sector 2, Lacul Tei Bvd., Bucharest, Romania
}

\begin{abstract}
Tube settler systems are one of the practical applications of the shallow sedimentation theory, which was originally developed to improve the performance of conventional sedimentation systems. The efficiency of these systems depends on multiple variables. In this paper, the influence of the tube settler unit at different inclination angles of $60^{\circ}, 54^{\circ}$, and $48^{\circ}$ and at different surface loading rates 2.4 to $0.42 \mathrm{~m}^{3} / \mathrm{m}^{2} . \mathrm{h}$ upon the coagulated particles has been investigated. A laboratory model has been designed and constructed for this purpose, which basically consists of coagulation-flocculation unit followed by tube settler unit. Tube settler unit consists of four separate circular tubes of $27 \mathrm{~mm}$ inner diameter, with a length of $150 \mathrm{~cm}$ each. Through the results, tube settler showed high efficiency in removing coagulated particles resulted from the chemical treatment of meat industry effluents. With respect to removal efficiency, it was observed that the change in the surface loading rate had a greater effect than the change in the inclination angle of the tubes. Also, the results indicated that there was a significant improvement in the flow pattern with the reduction in the Reynolds number, within the sedimentation unit, especially in the upper and lower zones of the tubes.
\end{abstract}

\section{Introduction}

Industrial waste is often released into soil or water bodies, thus greatly contribute to the degradation of the surrounding environment [1]. The food \& beverage industry is one of the biggest and an important sector in many countries, which have inevitably impact on the environment since it required considerable water resources and it is the most productive of the effluents per unit of production [2]. The meat industry is one of the vital sub-sectors of the food \& beverage industry, which often producing high polluted wastewater [3]. Meat industry effluents are heavily contaminated by carbohydrates, proteins, fats, organic acids. Macromolecules of the protein roll up into compact globules, which have a hydrated coating, and often acquire a negative charge [4].

Coagulation process intended to encourages suspension particles to join together and forming small aggregates called "Flocs", which are insoluble material and more likely to settle or to be trapped in the filter. Coagulation-flocculation is a complex process, involving destabilization of colloidal particles by the addition of a chemical reagent. The main source of the stability of the particles is the presence of an electrically charged layer on the surface of each particle [5]. Separation of the solid matters from the liquid is one of the main goals of most treatment processes, which have a significant impact on subsequent treatment processes and on the overall efficiency of treatment processes. Newton's and Stoke's laws are used to analyze discrete particle settling. Terminal settling velocity can be calculated according to the principle of Newton's law, by equating the frictional resistance, or drag force, on the particle, to the gravitational force of the particle. For the spherical solid particle, the law is:

$$
v_{t}=\left[\frac{4 g\left(\rho_{\mathrm{s}}-\rho\right) \mathrm{d}}{3 C_{D} \rho}\right]^{\frac{1}{2}}
$$

where: $\mathrm{v}_{\mathrm{t}}=$ particle settling velocity, $\mathrm{m} / \mathrm{s}, \rho_{\mathrm{s}}=$ density of particle, $\mathrm{kg} / \mathrm{m}^{3}, \rho=$ density of fluid, $\mathrm{kg} / \mathrm{m}^{3}, \mathrm{~g}=$ acceleration due to gravity, $\mathrm{m} / \mathrm{s}^{2}, \mathrm{~d}=$ diameter of the sphere, $\mathrm{m}$, and $\mathrm{CD}=$ drag coefficient.

Theoretically, $v_{t}$ value represented the difference in velocity between the particle and the liquid and it is independent of horizontal or vertical movement of the liquid [6]. Drag coefficient, $C_{D}$, is a variable value depending on whether the flow regime around the particle is laminar, turbulent, or transitional. Stokes' law explains the relationship between the settling rate and the particle diameter, where it can be used to describe the moving of spherical particles through a fluid under laminar conditions. In contrast to the discrete particles, there is no appropriate mathematical formula that can be used to describe settling velocity of flocculent particles, due to agglomerate of those particles with other during their settling, resulting in a continuously changing in size and shape for those particles.

Coagulated Particles may coalesce or flocculate during settling, therefore the shape factor is difficult to determine. Particles interact with each other forming new larger particles which they settle more rapidly than the constituent particles, these particles having loose and irregular structure, which is probably going to own a relatively large value of the shape factor [6]. Flocculation of the particles depends mainly on

\footnotetext{
* Corresponding author: Eng.sofyan2@gmail.com
} 
individual particle's opportunity for contact, which varies with different sedimentation processes, flow rate conditions, the depth of the basin, velocity gradients inside the system, particles concentration, and size ranges of the particle [7].

Sedimentation is one of the most economical separation methods, which utilize to separate organic and inorganic solids from waste/water, due to the difference in the densities between the suspension and the liquid under the certain conditions. The separation process can be done without the use of chemicals or by adding chemical substances (coagulants) which activate the process of removing solids materials by aggregation them to forming larger particles of their components and thus easy to remove them from water as in the present study.

Tube settler systems are relatively inexpensive technology predominantly used to enhance the performance of conventional sedimentation tank. Such systems usually used as sedimentation units in water or wastewater treatment plants, or they can be used to an upgrading of the existing conventional sedimentation tanks, to improve performance and to increase the capacity of the sedimentation tanks beyond original design conditions $[8,9]$. Tube Settlers are a practical application of the shallow-depth sedimentation theory, which consisting of bundles of small plastic tubes of various geometries usually installed at inclination angle ranging from 45 to 60 degree above the horizontal, that permits the settled particles to slide down towards the lower ends of the tubes, so the self-cleaning of those tubes will be achieved. They are used to enhance the settling characteristics of sedimentation basins. Tube settlers systems increase the settling capacity of the sedimentation basins by reducing the vertical distance a suspended particle must travel.

Tube settler systems occupy a small footprint compared with the conventional sedimentation basins, and this is a very important feature. In addition to it has an economic importance, it has another benefit, where provides an opportunity for the clarifier units to be installed and operated indoor, decreasing some of the problems related to algal growth, clogging due to blowing debris accumulation and odour control [10], as well such systems have an additional benefit of largely suppressing wind currents and significantly improve the flow pattern in the basin [11], so the turbulence will be minimized or even eliminated. Turbulence effectively obstructs the sedimentation of suspended particles, resulting deteriorates the quality of the effluent water and lowering the overall efficiency of the treatment plant. Flow regimes are usually classified according to their Reynolds number ( $R e)$, which is specified by using the following equation:

$$
\mathrm{Re}=\frac{\rho \mathrm{v} R_{h}}{\mu}
$$

where: Re, $v, R_{h}, \rho$, and $\mu$ are Reynolds number, water velocity $(\mathrm{m} / \mathrm{s})$, hydraulic radius, fluid density, and viscosity of the water respectively. Water velocity in the tubes can be calculated using the following equation:

$$
v=\frac{Q_{W}}{3600 \pi\left(\frac{d}{2}\right)^{2}}
$$

where: $v, Q_{w}$, and $\mathrm{d}$, are water velocity $(\mathrm{m} / \mathrm{s})$, water flow rate $\left(\mathrm{m}^{3} / \mathrm{h}\right)$, and pipe Inner diameter $(\mathrm{m})$.

According to Camp's model, the efficiency of the sedimentation basin depends upon the surface loading rate (SLR), the efficiency increase as the surface loading rate decrease [6].

$$
S L R=V_{C}=\frac{Q}{A}
$$

where: $\mathrm{Q}, \mathrm{A}$, and $\mathrm{V}_{\mathrm{C}}$, are flow rate $\left(\mathrm{m}^{3} / \mathrm{s}\right)$, surface area of the basin $\left(\mathrm{m}^{2}\right)$, and critical settling velocity $(\mathrm{m} / \mathrm{s})$ respectively. The surface loading rate in high rate settler can be calculated by the flowing equation:

$$
S L R=\frac{Q}{\sum A_{P}}
$$

where: $\mathrm{A}_{p}$ is the projected area of the tubes $\left(\mathrm{m}^{2}\right)$.

As a result of the acquisition of high- rate settling systems to a large settling area compared with traditional sedimentation basin, so these systems can be operated at higher surface loading rates than the conventional types.

\section{Materials and methods}

\subsection{Pilot plant}

Pilot-plant was fabricated and installed at Water Supply and Sewerage "Colentina" Laboratory - Technical University of Civil Engineering of Bucharest-Romania. The module mainly consists of individual, raw industrial wastewater tank, chemical addition unit, coagulationflocculation unit, and sedimentation unit; these units together provide a complete coagulation-flocculation and sedimentation treatment process. This pilot-model enables to study the coagulation, flocculation and settling processes separately or simultaneously. The actual view of the pilot model illustrated in Figure 1.

Sedimentation model consists of three connected sub-unit: inlet unit (distribution basin), tube settler unit and outlet unit. The first unit consists of two chambers, the largest ones represent the entrance chamber where the coagulated water enters through this chamber, is connected sideways to the sludge collection chamber. This unit is connected from the top by four circular tubes with a length of $150 \mathrm{~cm}$ each.

Tubes inclination can be modified to form angles of 60, 54, and 48 degrees with the horizon. Each tube settler has an inner diameter of $27 \mathrm{~mm}$ and crosssectional area of $5.7 \mathrm{~cm}^{2}$. The inlet unit is directly connected to the flocculation basin by a transfer tube with an inlet valve. The treated wastewater eventually collects in the collecting small basin located on the upper side of the outlet unit. Water flow can be controlled by a 
flow meter and a butterfly valve, the delivery of chemicals from the dosing tank to the coagulationflocculation unit can be controlled by two peristaltic pumps.

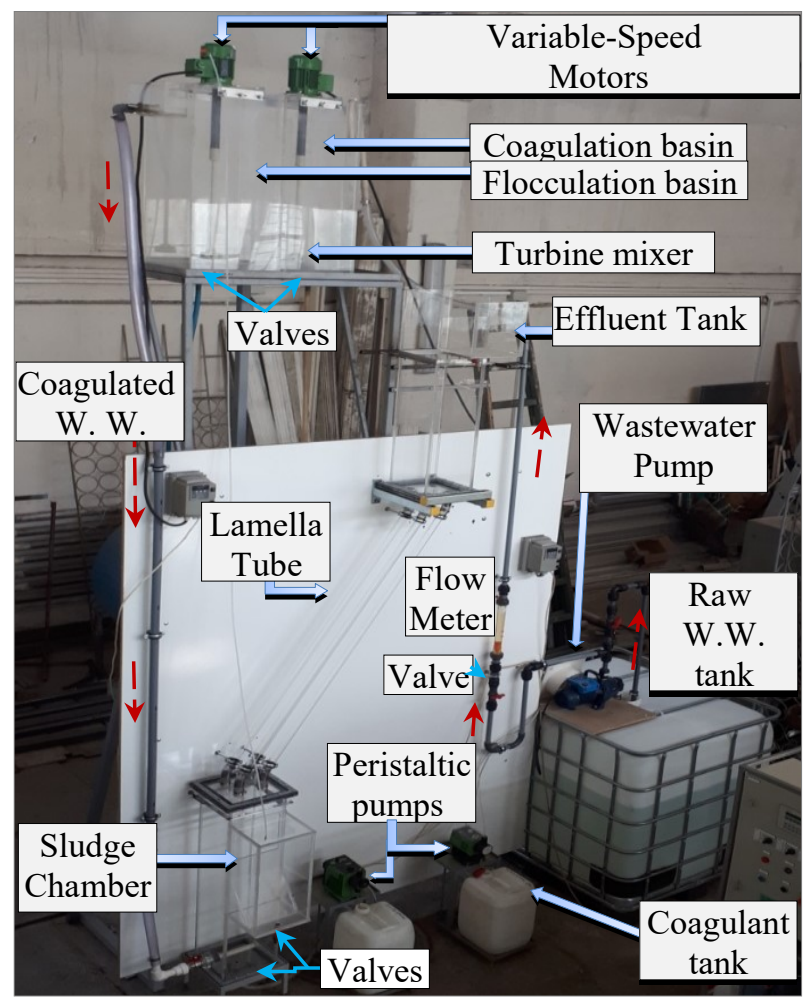

Fig. 1. Pilot scale model.

\subsection{Methodology}

Industrial effluents resulting from a meat processing plant was applied to operate the laboratory model. After a series of experiments using a jar test device, ferric chloride $\left(\mathrm{FeCl}_{3}\right)$ was showed high removal efficiency and subsequently applied to operate the pilot-plant at different surface loading rate (SLR) of 2.4, 1.8, 1.2, 0.6, and $0.42 \mathrm{~m}^{3} / \mathrm{m}^{2} . \mathrm{h}$.

\section{Results and discussions}

The first operation cycle was conducted at surface loading rate (SLR) of $2.4 \mathrm{~m}^{3} / \mathrm{m}^{2}$.h where the pilot plant model was operated at this surface loading rate with the inclination angle of $54^{\circ}$ with the horizontal for the tube settler unit. From the experimental operational, it was observed that large portion of the suspended particles (flocs) rushed strongly towards the top of the tube settler unit and they arrived into the treated effluent basin, where the water velocity has exceeded the settling velocity of most particles, therefore, the tube settler unit was unable to capture most of them, Therefore, the results of the removal efficiency at this flow rate were neglected. Figure 2 illustrates the particles within the tube at this flow rate.

Another operation cycle was conducted at SLR of $1.8 \mathrm{~m} / \mathrm{h}$; a constant flow rate was applied to operate the model, while the inclination of the tube settler unit was adjusted to be $60^{\circ}, 54^{\circ}$, and $48^{\circ}$ with horizon for each operating cycle. From the obtained results, the removal efficiency of the turbidity over time during operation the pilot model at different inclination angles for the tube settler unit was plotted as is shown in figure 3 .

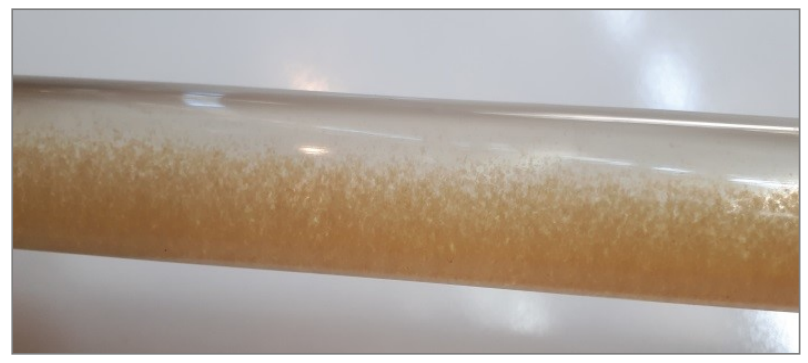

Fig. 2. Flocs flow in the intermediate section of the tube settler (SLR $2.4 \mathrm{~m}^{3} / \mathrm{m}^{2} . \mathrm{h}$; inclination angle of $54^{\circ}$ ).

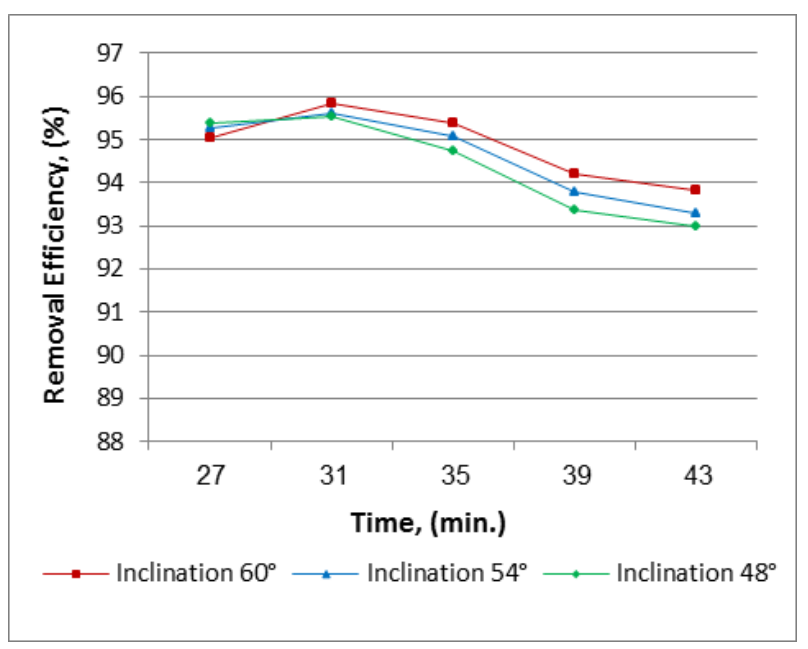

Fig. 3. Percentages of turbidity vs. time (SLR $1.8 \mathrm{~m} / \mathrm{h}$ ).

It was noticed during the operation of the model at this loading rate, there is a transition zone at the lower ends of the tubes extend to a distance of about $25 \mathrm{~cm}$, It was also observed that the sedimentation of Flocs in the transitional areas (upper and lower zones of the tubes) was very limited. The effective sedimentation area occupied an extended area in the middle zone of the tubes beyond the turbulence zones, thus the effective settling zone occupied an approximate length of less than $120 \mathrm{~cm}$.

Water velocity was relatively high led to the appearance of a disturbance zone at the lower zones of the tubes. The water currents were formed waves at those zones of the tubes and it's led to re-suspension of the settled particles (Flocs) and brought a portion of them back to the water stream. It was observed that the sliding sludge faced a strong current of water as it slid down of the tubes (as is shown in Figure 4), so a large portion of sliding particles prevented to complete their paths towards the sludge collector chamber. This led to deterioration in the quality of the treated effluents, after a period from the beginning of running of the pilot model.

The behaviour of the sliding sludge during the operation of the laboratory model at different inclination angles of the tube settler unit was observed. At inclination angle $60^{\circ}$, the movement of the sliding sludge on the bottom surface of the pipes was clearly visible and continuously, at the upper and middle zones of the 
pipes despite of the relatively high velocity of the water current which has opposite direction of the sliding sludge, while, in the lower parts of the tubes especially near the lower ends, the sliding sludge faced a turbulent stream. This stream has been a strong impact upon the sliding sludge and it was caused dissipate the accumulated sludge. This turbulence was constituted a real obstacle to accumulated sludge to complete the path toward the lower ends of the tubes.

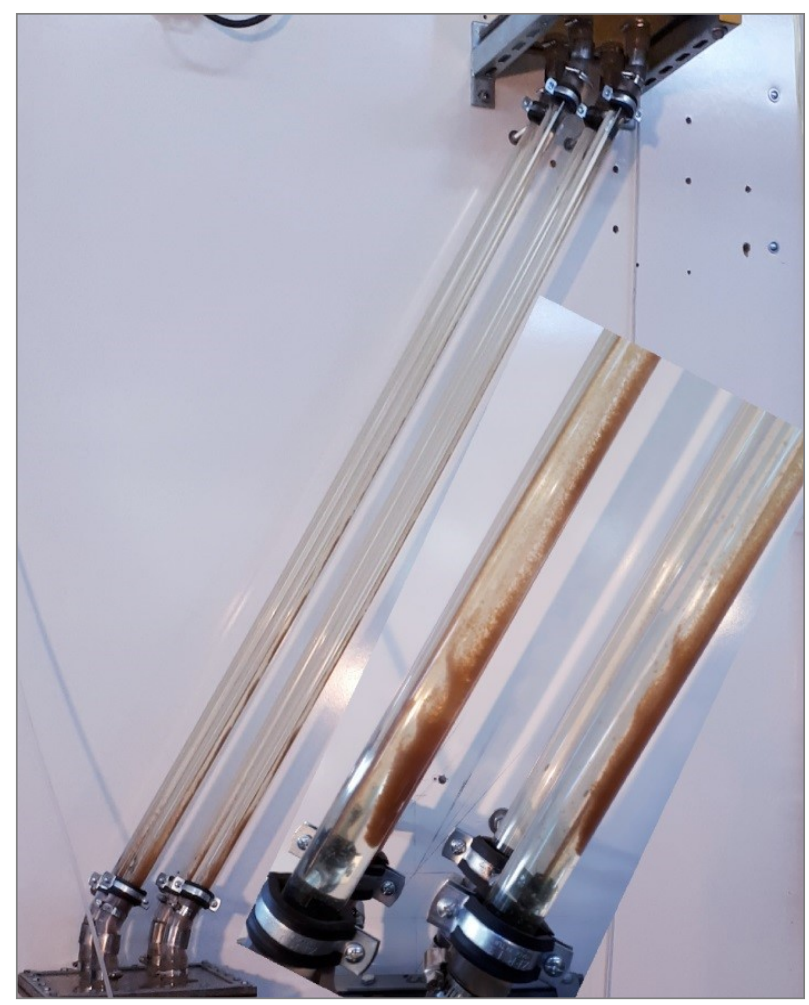

Fig. 4. Effect of turbulence at lower zone of the tubes on the sliding sludge (SLR $1.8 \mathrm{~m}^{3} / \mathrm{m}^{2} . \mathrm{h}$; inclination angle $60^{\circ}$ ).

The same was observed when the inclination angle of the tubes was modified to be $54^{\circ}$, but the effect of the disturbance on sliding sludge was somewhat more influential. At the inclination angle $48^{\circ}$, it has been required a larger accumulation of the sludge on the bottom surface of the pipes to increases their mass to start sliding down, and this requires the sedimentation of more particles on the surfaces of internal tubes. The effect of the water currents in the lower zones of the tubes settler was clearer on the sliding sludge at the inclination angle $48^{\circ}$ than its effect at the angle of inclination $60^{\circ}$, where the water current succeeded in achieving a greater penetration of the sliding sludge at the inclination angle 48, and thus more dispersion and further re-suspension settled particles (Flocs).

The settled sludge in both the entry chamber and the sludge collection chamber has not settled under the compressive category, where the concentration of the particles and available retention time in addition availability of the relatively quiescent condition, represent the critical factors to sedimentation under this category, where the relatively high velocity of the coagulated water flowing through the conveyor tube from the coagulation unit to the sedimentation basin contributed to a limited disturbance at the lower zone of the inlet basin.

A large portion of the large-sized particles (Flocs) took their path towards the bottom surface of the tubes then to the sludge collection chamber, which their settling velocity was higher than the water velocity, this is due to the fact, that these particles have a high molecular weight, that allowed them to overcome the velocity of the water stream, while the smaller particles and due of lightweight could not resist the flow velocity, so water was continued to carry them upward. Some of these particles were settled at upper zones of the tubes while the rest succeeded in escaping from the tube settler unit and finally reached to the outlet basin. Figure 5 illustrated the settled particles at upper zone of the tube settler.

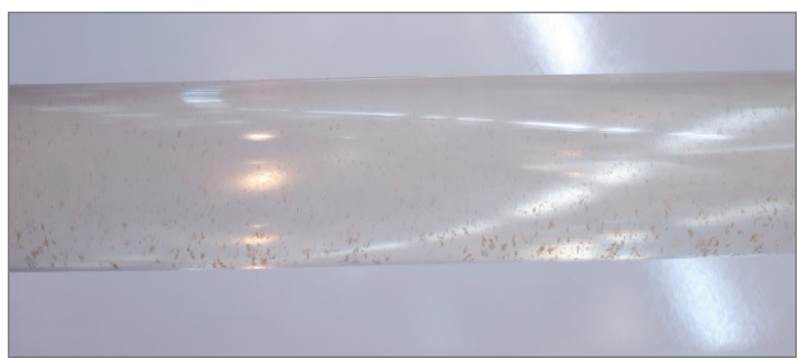

Fig. 5. Particles settled at the upper section of the tube settler (SLR 1.8 of $\mathrm{m} / \mathrm{h}$; inclination angle $60^{\circ}$ ).

New cycles were conducted to operate the pilot model at a SLR of $1.2 \mathrm{~m}^{3} / \mathrm{m}^{2} . \mathrm{h}$ at different inclination angles $\left(60^{\circ}, 54^{\circ}\right.$, and $\left.48^{\circ}\right)$ for the tube settler unit to study the effect the reduction in the loading rate with the change in the inclination for the tube settler unit on the efficiency of removal of pollutants. It is noticeable from Figure 6 that there is an improvement in the removal efficiency, compared to the previous operation cycles at SLR of $1.8 \mathrm{~m} / \mathrm{h}$.

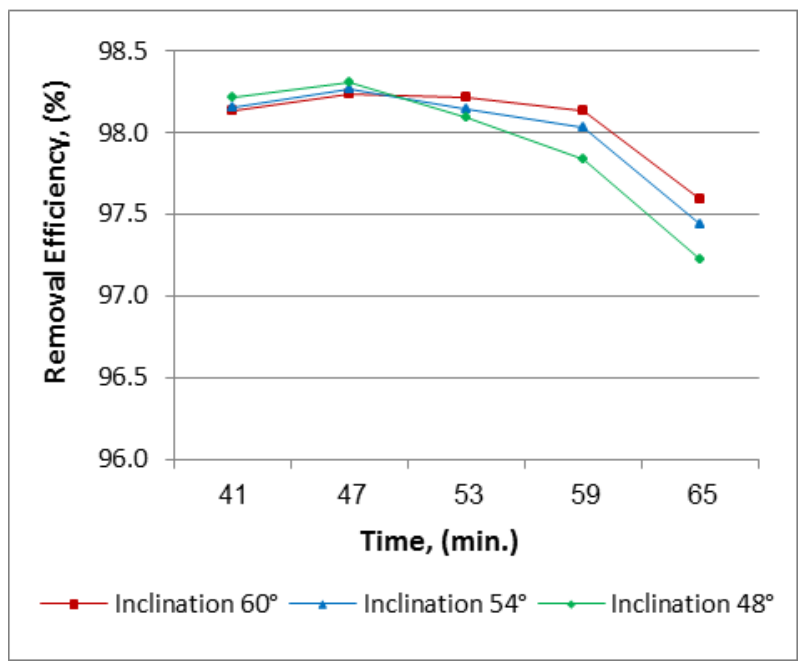

Fig. 6. Percentages of turbidity removal vs. time (SLR $1.2 \mathrm{~m} / \mathrm{h}$ ).

The reduction in the loading rate led to decrease the velocity of the water, so a large portion of the particles that having settling velocities equal or greater than water velocity was captured it in the tube settler unit. In addition that, the reduction in the flowing velocity of the 
coagulated water during its movement from coagulationflocculation unit to the inlet settling unit reduced the turbulence at the lower zone of the inlet unit this provided more suitable conditions for sludge to settle in a smoother manner compared with the previous experiences at a loading rate of $1.8 \mathrm{~m}^{3} / \mathrm{m}^{2} . \mathrm{h}$. The settled sludge in the inlet unit was contributed to some improvement in the removal ratios by entrapping a portion of the large Flocs in the amorphous of the settled sludge and prevented them from completing their path towards the outlet unit.

The pattern of the sedimentation of the particles on the bottom surfaces of the settling tubes and the method of their spread along the tube settler varies at the beginning of the operation the model than its pattern after a period of time. At the beginning of the operating the model, particles start to settle as scattered particles along the settling zone of the tubes, as is showed in figure 7 which is illustrate the settled Flocs at the bottom surface of the tubes at inclination angle $60^{\circ}$ with the horizon. These particles represent the portion that succeeded in penetrating the settled sludge in the inlet chamber and reaches the tube settler unit, that later was captured in the effective settling zone of those tubes.

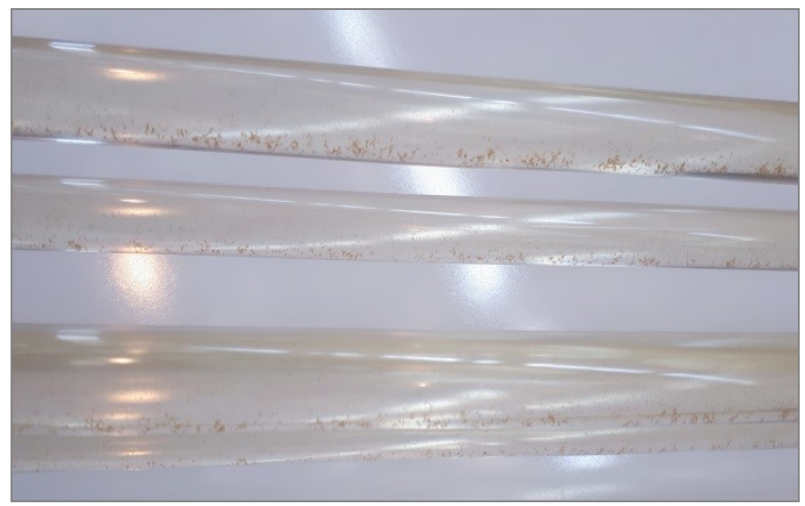

Fig. 7. Settled particles at bottom surface of the middle section of the tube settler at (SLR $1.2 \mathrm{~m} / \mathrm{h}$; inclination angle of $60^{\circ}$ ).

From the visual observations, it was observed that the length of the transition zone was retracted to about of 20 $\mathrm{cm}$ at the lower zones of the tubes and about $5 \mathrm{~cm}$ at the upper parts of the tubes, where no accumulation of particulate matter was observed in those zones of the tubes, which we can be called the "non-effective zone". As mentioned above, the coagulated particles (Flocs) settled as individual Flocs, then after they begin to accumulate gradually and they formed a masses separated from each other, the spread of these masses was along the tubes except in the "non-effective zones".

The term "effective zone" can be called to parts of the tubes settler that have been effective in capturing the suspended particles, due to the presence of an appropriate flow pattern at those zones, which allowed for the suspended particles to settle on the bottom surfaces of those zones. Those zones extend to include most of the length of the sedimentation pipes except for the parts that are characterized by a disturbed or transitional flow. Figure 8 illustrates the settled particles as masses separated from each other and the spread of those Flocs masses in certain zones of the tubes. This can be explained, by the fact that most large particles (Flocs) were settled in the inlet unit or they entrapped by the settled sludge with the amorphous of the settled particles, while the most of medium and small particles were succeeded escaping from the inlet unit and they flowed in their paths towards the settling tubes, and due the fact that these particles have a somewhat low partial weight (have a low settling velocity), it is difficult to settle these particles with existing a relatively high flow velocity or with a presence of turbulent or transition flow regime within the tubes. But with a presence sufficient length of tube settlers, these particles have been settled in the middle or upper parts of the tubes, depending on the mass weight of those particles, as well depending upon the type of the flow regime in those zones.

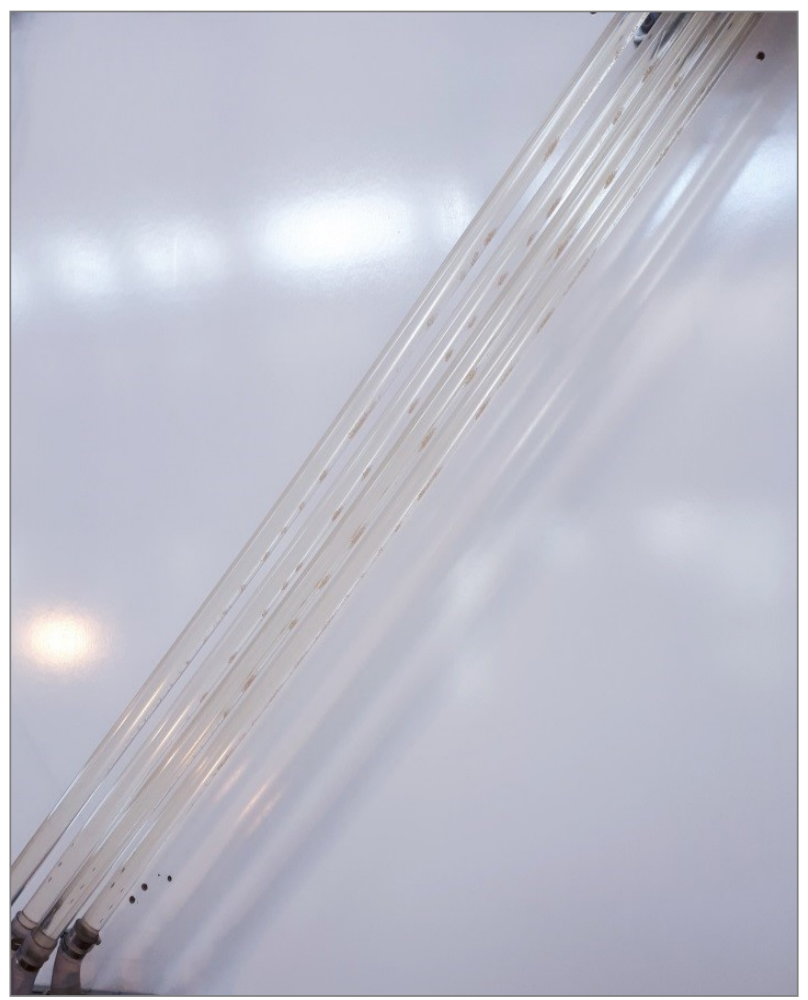

Fig. 8. Masses of settled particles at the bottom surface of the tube settler (Inclination angle of $48^{\circ}$ ).

The length of the "effective" and "non-effective" zones and their respective ratio to the total length of the tube is not constant and depends on several factors, the most important is the flow regime inside the tubes in addition the inclination of the tubes settler unit, where it was observed under the same operating conditions that the "non-effective" was longer when the inclination of the tube settler unit was $60^{\circ}$ than its length at the inclination angle $48^{\circ}$ at the same flow rate. Figure 9 illustrates settled particles as amasses at the bottom surface of the tubes when the tube settler was inclined at $60^{\circ}$ with the horizon.

The particles weight, inclination angle of the tubes, shear force, and in addition to the fluid viscosity are the determining factors for sliding of the settled particles on the bottom surfaces of the tube settler, So the settled solids on the bottom surface of the tubes start to slide 
toward down when the weight component for the particles or the accumulative Flocs in the parallel direction to the tubes or plates outperform all forces in the opposite direction $(\mathrm{mg} \sin (\theta)>\Sigma$ of the resistance forces). This requires either increasing the weight (Greater accumulation of the settled particles) or increasing the value of the inclination angle of the tube settler unit or increasing both of them if the other factors are constant. Figure 10 illustrates the relationship between accumulated particles and the shear force.

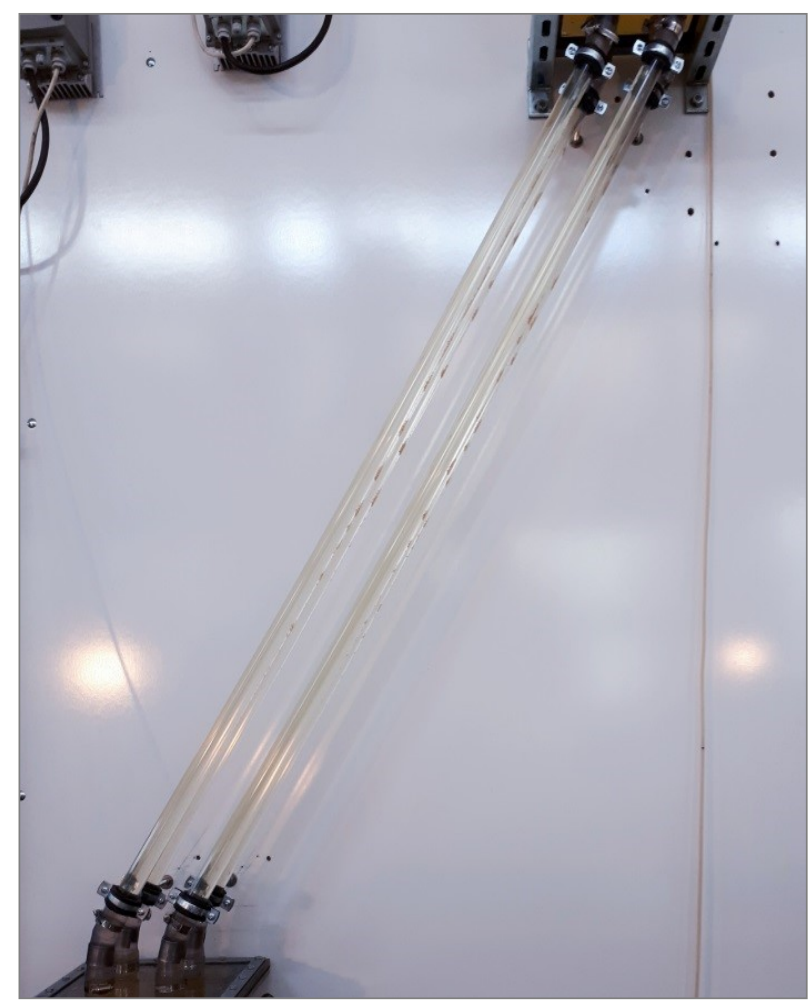

Fig. 9. Masses of settled particles at the bottom surface of the tube settler (Inclination angle of $60^{\circ}$ ).

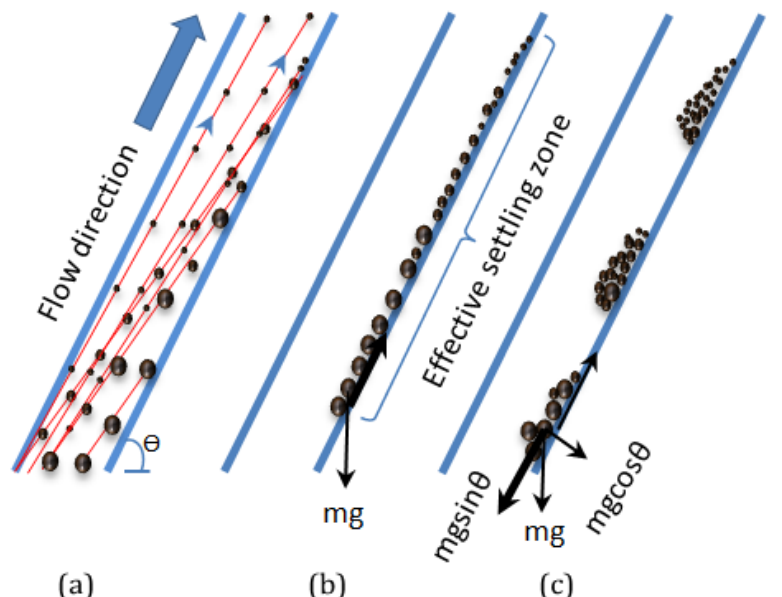

Fig. 10. Particle Removal Phases: (a) Paths of Different Particle Sizes, (b) Accumulated Particles on the bottom Surface of The Lamella (mgsin $\theta<$ shear force), and (c) Sludge Sliding $(m g \sin \theta>$ shear force).

In order to slide the accumulated sludge on the bottom surface of the tubes which has a low inclination angle, the mass of sludge must be increased, compensate for the low tendency of the pipe unit. Thus the weight component $(\mathrm{mg} \sin (\theta))$ will be increased. Increasing the accumulated particles on the bottom surface of the tubes are often accompanied by an increase in the thickness of those accumulations, so the cross-sectional area of the tubes will temporarily reduce by particle accumulation especially with the using tubes having a small crosssectional area. In this case, increasing the thickness of the accumulated sludge within the tubes will increase the effect of water currents upon its. As is known the velocity of the hydraulic fluid in a pipe is the result of the flow rate divided by the cross-sectional area of the pipe: $v=Q / A$, The output of this equation represents the average velocity $\left(\mathrm{V}_{\mathrm{avg}}\right)$ of all the fluid molecules moving through the pipe. The velocity profile of the liquid within a pipe changes from zero at the inner surface of the pipe to a maximum at the pipe middle, where a thin layer of fluid next to the inner walls of the tube does not move at all. For fully developed laminar pipe flow, the average velocity is half of the maximum velocity; figure 11 illustrate velocity profile in pipe [12].

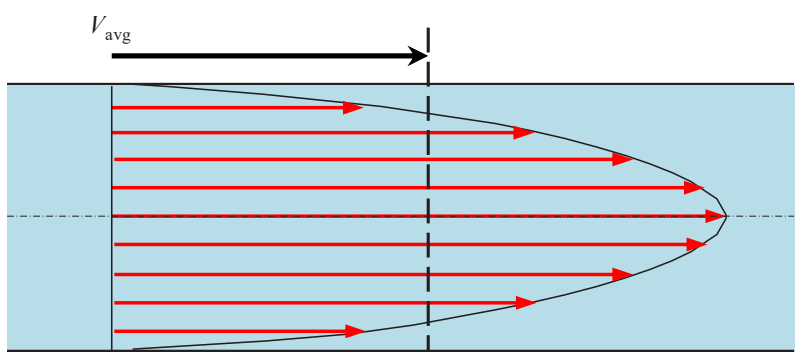

Fig. 11. The velocity profile of fluid in a pipe (laminar).

Thus, increasing the thickness of the accumulating sludge on the inner surface of the pipes has a negative effect on the characteristics of the flow and thus on the effluent quality. This effect is often more pronounced in pipes with small diameters. The continuous slippage of the sludge at the inclination angle of $60^{\circ}$ reduce the accumulative thickness of the settled sludge on the bottom surface of the settling tubes and thus to somewhat reduce the effect of the water current. This helped to a certain extent to improve the removal efficiency of the pollutants at this inclination angle when the laboratory model operated for long periods.

Most of the large-sized particles (flocs) were settled at the tube surface and finally settled down in the sludge collection chamber, where the settling velocity of those particles was equal or higher than the water velocity. this due to the fact that these particles have a high molecular weight that allows them to overcome the flowing water inside the tubes, while the most of the smaller particles and due of its light weight could not resist the flow velocity, so those particles continued in their movement upward towards the outlet basin. Thus, if short tubes were used in the tube settler system, most of these particles cannot be captured, which usually required an appropriate length of the tubes to settle on the bottom surfaces of the settler unit; therefore, the length of the tube is a crucial factor in the settling of those particles. In the early period of operation of the laboratory model, the coagulated particles begin to settle gradually along 
the effective zones of the tubes as individual particles, (Figure 7), and then, with the continued operation of the laboratory model for a certain period, more particles will settle on the bottom surface of the tubes, as a result, Non-connected groups will be formed spaced each other about. At this loading rate the separation space between the accumulated particles was ranging from 2 to $13 \mathrm{~cm}$. Figure 12 illustrated these agglomerations at the bottom surface of the tube settler unit.

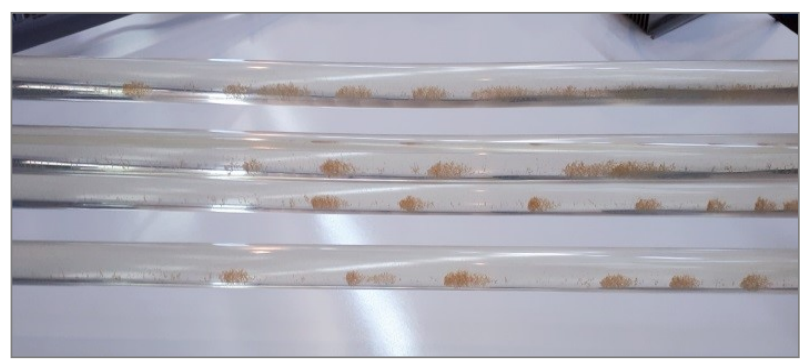

Fig. 12. Masses of the settled particles at the bottom surface of the tube settler (Inclination angle of $60^{\circ}$ ) (Flow direction from right to left).

With the continued operation the laboratory model for a longer period, more particles will settle to tubes surfaces and thus the growth of settled masses increases gradually till reached to a critical point, where the weight component is equal the shear force. After this point, the settled particles begin to slide downward, and during its movement, they sweep out the individual particles or the aggregated masses which located on their way towards the lower end of the tube. Figure 13 shows the first stages of the convergence of two separated masses as they move downwards to form a larger mass.

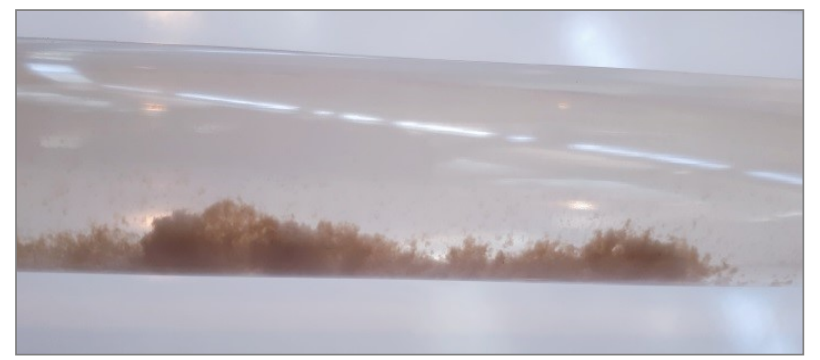

Fig. 13. Two masses of the sludge began to merge together and forming a larger mass (Inclination angle of $54^{\circ}$ ).

During sliding of the sludge upon the bottom surface of the tubes, sludge exposed to dispersion as it moves down, where if the water velocity inside the tubes is fairly high, water current tries to disassemble the sliding sludge to their components and to re-suspend the settled particles and then tries to return them back into the water stream up towards the upper part of the tubes. Depending on the strength of the water current, portions of disassembled sludge try to re-settle on the bottom surface of the tubes. Since the sliding particles already have good settling properties [13], while the fine smaller fractions may succeed in leaving the tube settler unit. This phenomenon was observed when the laboratory model was operated at a loading rate of $1.8 \mathrm{~m}^{3} / \mathrm{m}^{2} . \mathrm{h}$, as well as at a loading rate of $1.2 \mathrm{~m}^{3} / \mathrm{m}^{2}$.h but to a lesser degree. This phenomenon was more pronounced in the transition and disturbance zones within the tubes than other zones. Figure 14 illustrates the effect of the water current on the sliding sludge at the bottom zone of the tube settler at a loading rate of $1.2 \mathrm{~m}^{3} / \mathrm{m}^{2} . \mathrm{h}$.

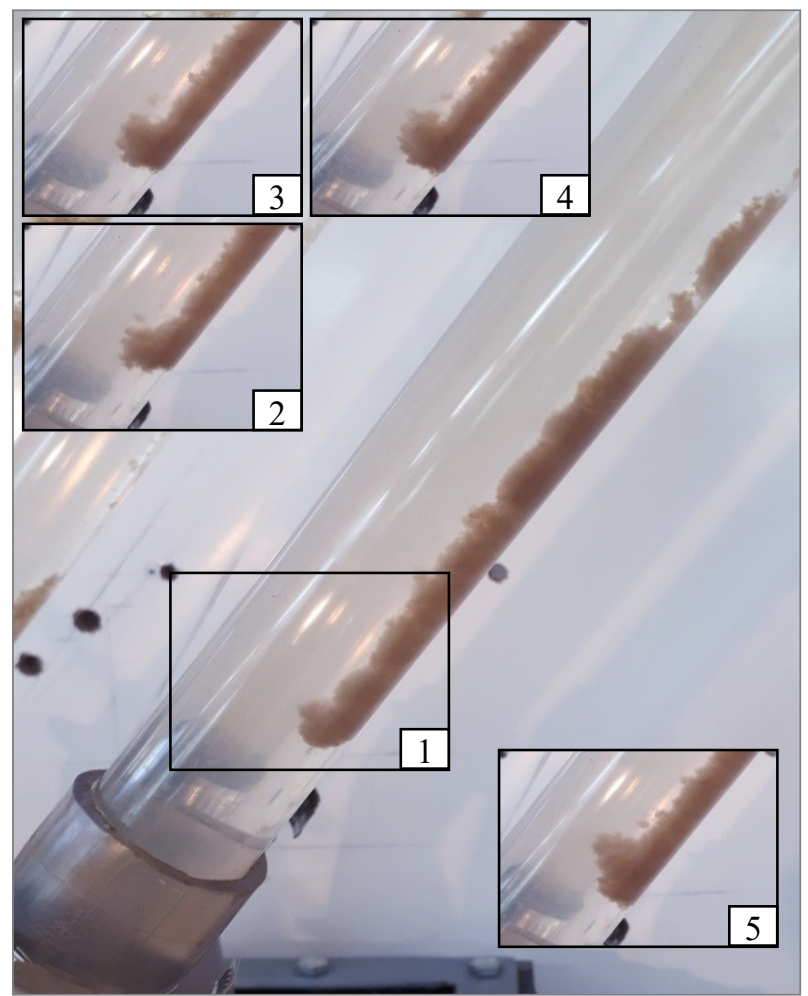

Fig. 14. Sliding sludge down towards the sludge collection chamber (Inclination angle of $54^{\circ}$ ).

The sliding sludge can be exposed again to the fragmentation during its movement, where when the sliding sludge falls down from the tubes towards down into the inlet unit. The sludge masses exposed to a random fragmentation under the influence of the water currents under the lower ends of the tubes; large fractions continue their paths down until reached to the sludge blanket in the inlet chamber, and finally they will settle down at the sludge collection chamber and later can be disposed outside of the pilot plant. While smaller parts (individual fine particles or flocs) may return back to the tubes if the water velocity is high. Figure 15 shows several fragmented masses of the sludge which were fallen down within the inlet chamber after leaving the lower ends of the tubes.

Fragmentation of sludge masses below the tubes settler unit depends on several factors includes, the quality of the wastewater, chemicals quality, the length of the falling path, and the determinant factor is the amount of disturbance of the carrier medium (water) under the tubes unit and at the entrance of those tubes. where if there is a high disturbance zone under the tube settler unit, water stream will work to break up sludge into small masses or to individual fine particles, such these fine Flocs, it easy to carry and return them to the water stream, and maybe could not be captured by the tube settlers, thus negatively affects upon the quality of treated water. The rapid change of the local boundaries 
surrounding the water as it moves from one place to another will led to change in the flow state and the velocity distribution as well creating a vortex region [14], so improving the hydraulic conditions under the tube settler unit, and in the inlet unit, will improve the overall performance of the tube settler unit.
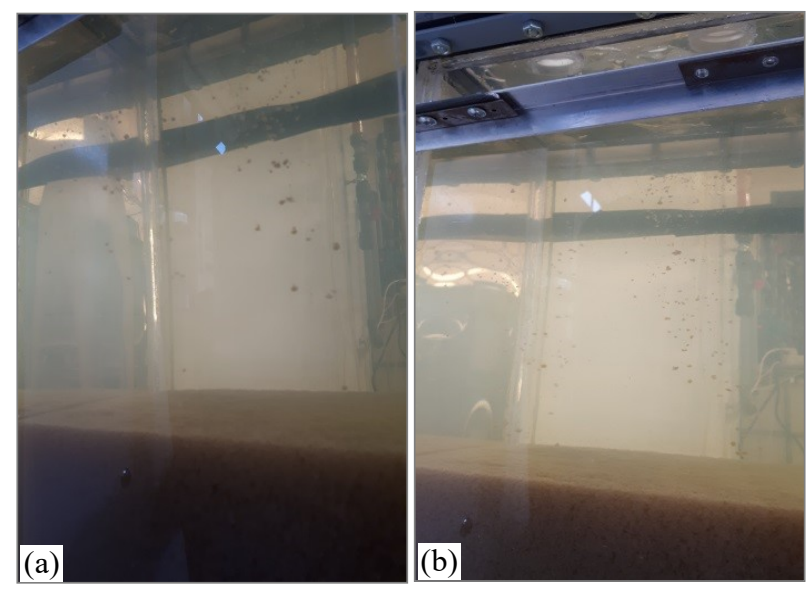

Fig. 15. The accumulated sludge leaves the tube settler unit; (a) large fractions (clumps), (b) small fractions.

An additional reduction in the loading rate was adopted to operate the laboratory model to be $0.6 \mathrm{~m}^{3} / \mathrm{m}^{2} . \mathrm{h}$ and the impact of this reduction on the removal efficiency at different inclination angles for the tube settler unit was measured. Figure 16 graphically illustrates the removal efficiency of the turbidity over the time for the model at inclination angles of $60^{\circ}, 54^{\circ}$, and $48^{\circ}$ for the tube settler unit.

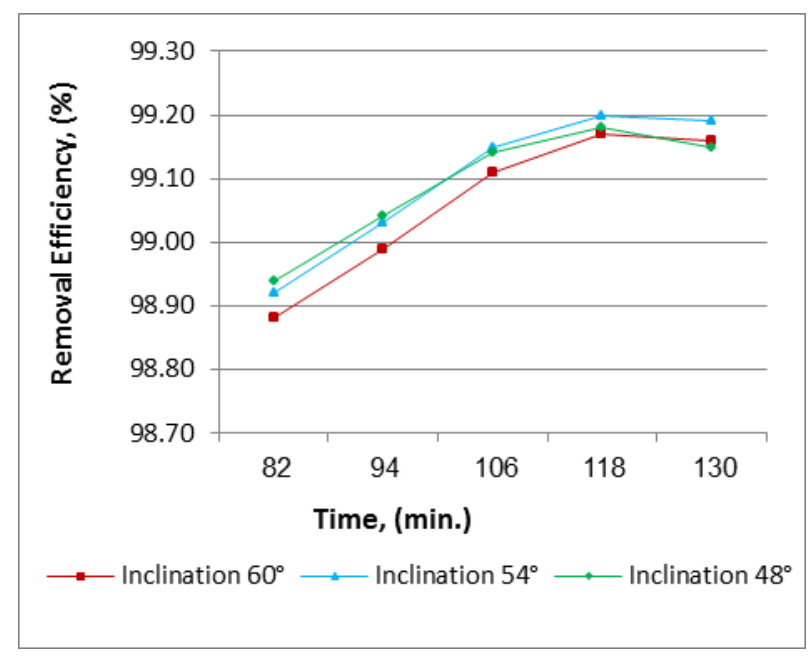

Fig. 16. Percentages of turbidity removal vs. time (SLR 0.6 $\mathrm{m} / \mathrm{h})$.

Through visual observations, it was observed that the non-effective settling zone in the upper and lower zones of the tubes was diminished, to less than $15 \mathrm{~cm}$ at the lower zones and to $5 \mathrm{~cm}$ at the upper zones of the tubes. Where it was observed the presence of settled particles at a distance of 15 , and $5 \mathrm{~cm}$ away from the lower and the upper ends respectively, while no sediment was observed in these zones in the previous operating cycles, where it was classified as ineffective settling zones, in other words, the effective settling zones (effective length) of the tubes at this flow rate increased than the previous operating cycles. This indicates an improvement in the flow regime in those zones. Figure 17 shows the settled particles at the lower zone of the tubes.

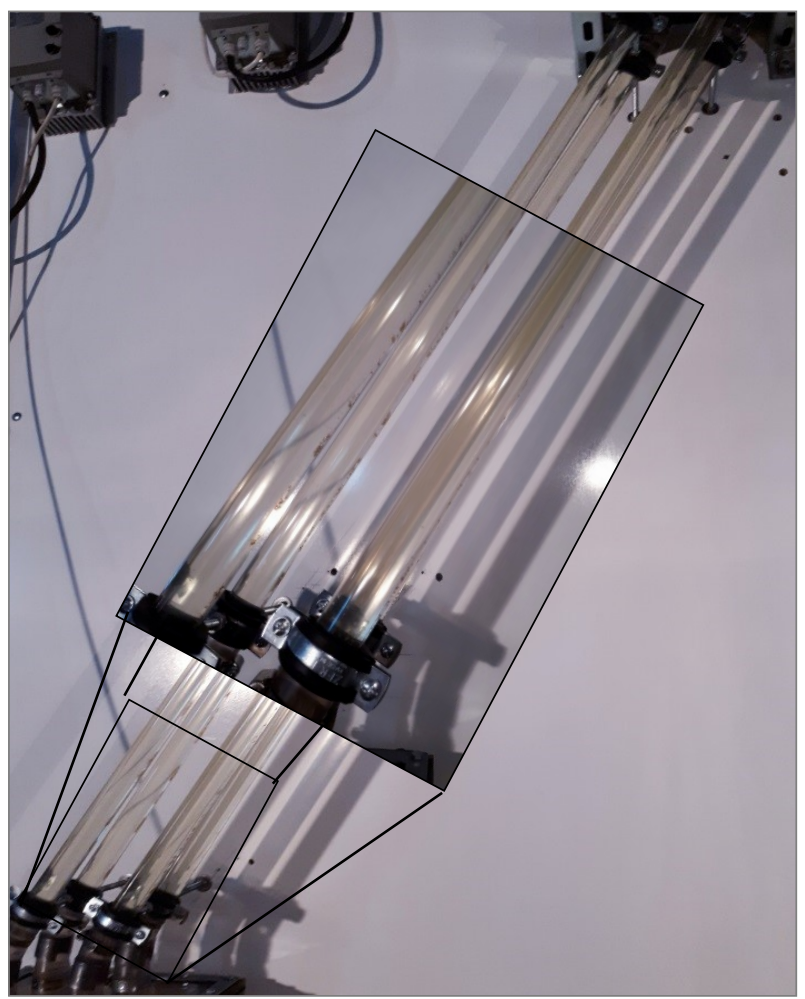

Fig. 17. Particles settled at the lower end of the tubes (Inclination angle of $60^{\circ}$ ).

An improvement in the quality of the treated wastewater was achieved at this loading rate since a larger percentage of coagulated particles were eliminated due to the reduction in the flow velocity either by capturing them in the tube settler unit it or by entrapping them in the amorphous of the settled Flocs. As well the reduction in the velocity of the flowing water to the inlet unit led reduced the disturbance in that unit, which has created the conditions for the particles to settle in a smoother pattern away from the disturbance, which contributed in some way to prevent the large particles (Flocs) from passing through it, which reflected positively on the quality of treated effluents. While the small and soft particles were succeeded in penetrating the settled sludge and continued its paths towards the tube settler unit. The significant reduction in the water velocity made the flowing current unable to carry most of those particles for longer distances. Therefore, these particles took their paths toward the bottom surfaces of the tubes; In the beginning, most of these particles were settled in a diffuse manner and along the effective settling zones of the tubes and then they started to slide down in very slow motion but for a limited distance within the tube, after that and during operation the model for a relatively long period, more particles joined with the settled particles, as a result, a small masses spaced 
apart each other were formed (figure 18), these masses usually slide more rapidly than it components.

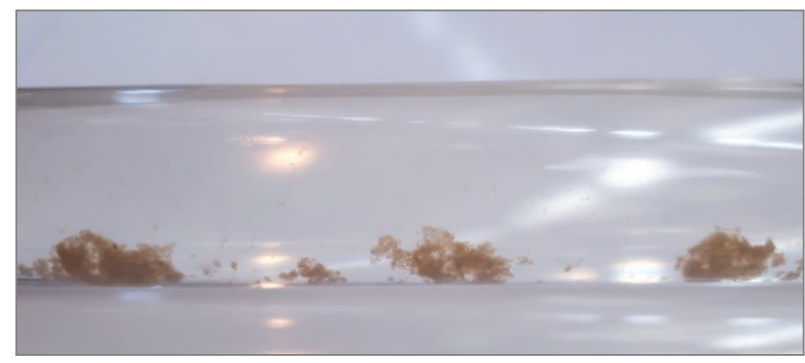

Fig. 18. Particles settled as small groups spaced apart (Inclination angle of $54^{\circ}$ ).

These masses continued to grow with the increase in the number of settled particles which Joined to them until they reached a critical point, and when the weight component of each mass exceeded the shear resistance, they begin to slide down. The formation of this separated masses took a longer period than it is in the previous operating cycles, this is due to the reduction in the concentration and the size of the particles that entering tube settler unit compared to previous operating cycles. There was another difference from the previous operation cycles, where the suspended particles were settled within zones from the tubes (zones near the lower and upper ends of the tubes) which were classified as non-effective settling zones in the previous operating cycles. This clearly indicates that there is an improvement in the flow regime in those zones, which allowed for the deposition of more particles in those areas compared to previous operating cycles. Figure 19 illustrate widespread of these masses along the length of the tubes.

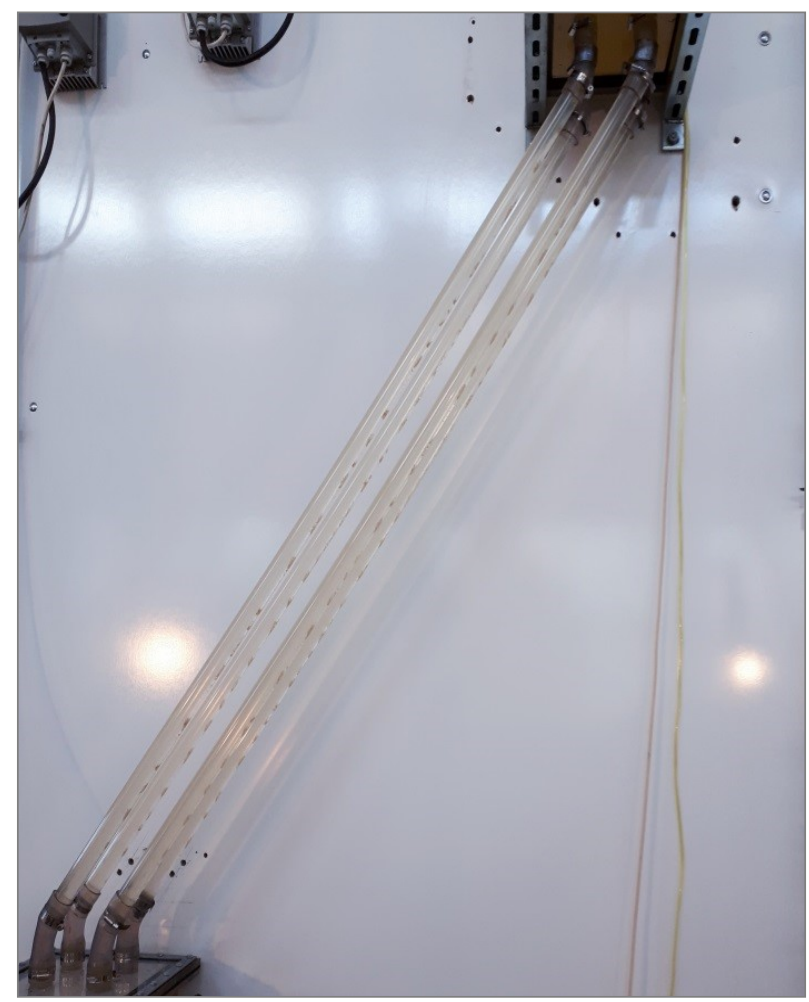

Fig. 19. Masses of settled particles at the bottom surface of the tube settler (SLR $0.6 \mathrm{~m} / \mathrm{h}$; inclination angle of $54^{\circ}$ ).
The last operating cycles were conducted with an additional reduction in the loading rate has been made, so the laboratory model was operated with SLR of 0.42 $\mathrm{m}^{3} / \mathrm{m}^{2}$.h to compare the effect of the flow rate on the performance of the pilot plant. The removal efficiency of the turbidity over time as well was measured, at inclination angles of $60^{\circ}, 54^{\circ}$, and $48^{\circ}$ for the tube settler unit, and the relationship between them was plotted as shown in figure 20 . The quality of treated water was significantly improved at this flow rate, where the highest rates of removal were obtained compared to previous cycles. In general at this flow rate, it was observed there was a convergence in the removal ratios for all inclination angles, and the results were tended to be more stable, and this is due to the significant improvement in the flow regime within the tubes compared with the other loading rates used in the operation of the laboratory model. The additional reduction in the flow velocity within the sedimentation unit resulted in a greater harvest for the coagulated particles, either by settling them or by trapping them at the atmosphere of the settled particles in the inlet unit.

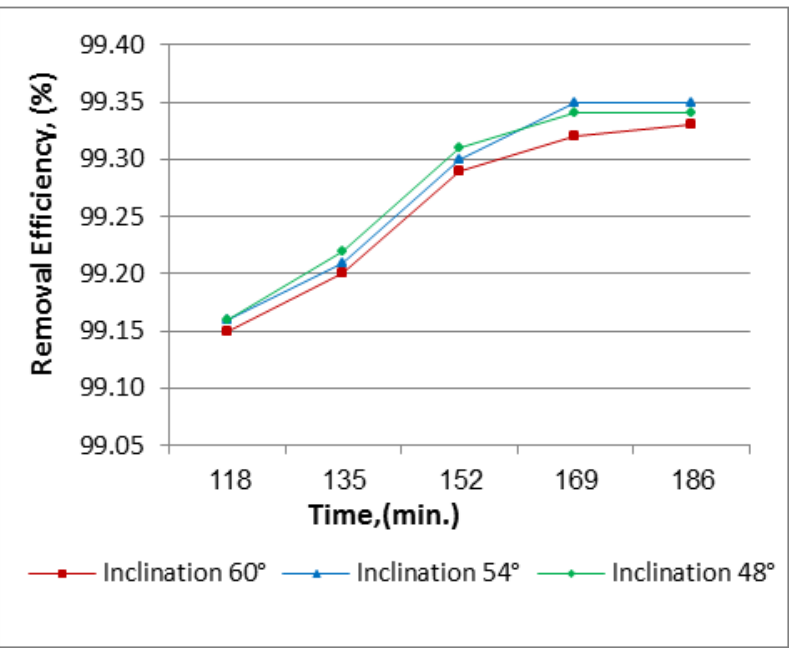

Fig. 20. Percentage of turbidity removal vs. time (SLR 0.42 $\mathrm{m} / \mathrm{h})$.

Small and very soft particles were succeeded in escaping from settled sludge in the inlet unit and they reached the tube settling unit, due to their low weight which allowing carrying it easily by water stream for longer distances, but with a relatively low velocity of the water within the tubes, most of those particles which having a settling equal or greater to flow velocity were captured in the tube settler unit. As in previous operating cycles, those particles were settled in a diffuse pattern along the effective zones of the tubes, but the difference here is the small size of settled particles (lighter particles), compared to those in previous cycles which cannot be captured at high loading rate. Where small and soft particles pose a major challenge to many sedimentation systems due to the low-density difference between them and water. Figure 21 illustrates the settled small particles at the bottom surface of the tube settler unit at this loading rate. 


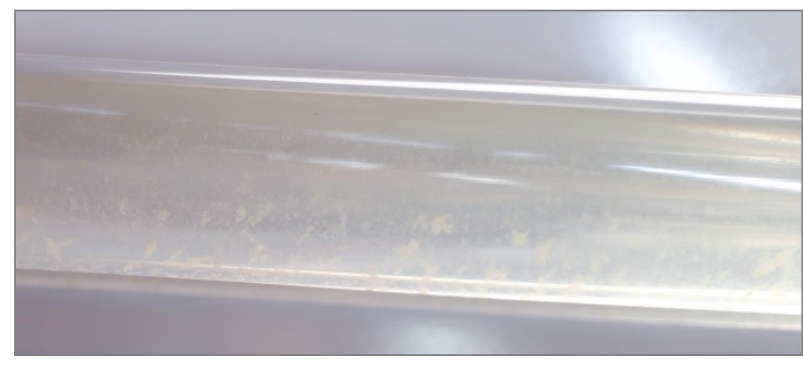

Fig. 21. The Settled small particles at the bottom surface of the tube settler (SLR $0.42 \mathrm{~m} / \mathrm{h}$; inclination angle $60^{\circ}$ ).

Particles continued to settle on the inner surface of the tubes, and as a result of the low concentration of suspended particles (Flocs) in the flowing water through the tube settler unit, and the small size of these particles, the accumulation process for those particles requires a relatively long period compared with the previous operation cycles. Initially, particles were settled in a different pattern than previous operation cycles as is shown in figure 22.

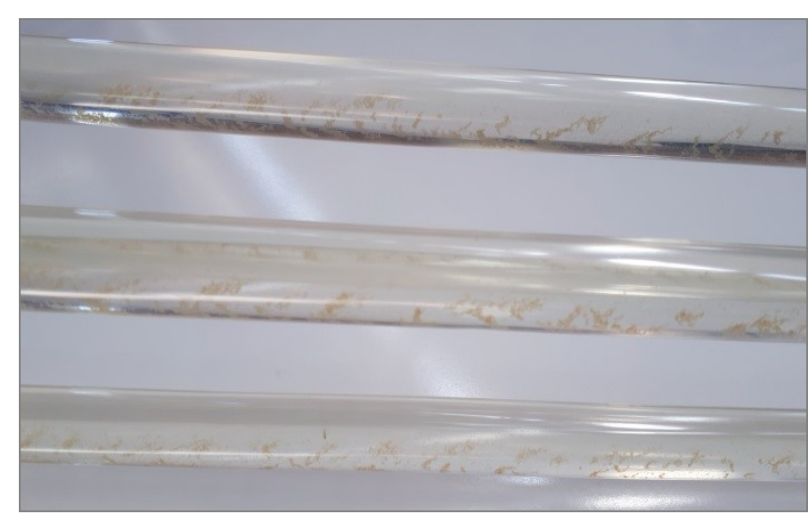

Fig. 22. The pattern of the settled particles (Flocs) at the bottom surface of the tube settler (SLR $0.42 \mathrm{~m} / \mathrm{h}$; inclination angle $48^{\circ}$ ).

The continuous running of the laboratory model for long periods brought more particles to the bottom of the tubes; as a result, separate masses of the settled particles will form. These masses are formed due to the slow movement of those particles on the bottom surface of tubes towards down in addition to the further sedimentation of the suspended particles, and which joins to those settled particles. At this loading rate, the formed masses were spaced from each other by a distance of 2 to $7 \mathrm{~cm}$, which took long periods to form them compared to what was observed at previous operation cycles at higher flow rates. Figure 23 shows a number of these masses on the bottom surfaces of the tubes.

It was observed that those particles settled along the almost length of the tubes this indicates that effective settling zones in the tubes have largely expanded. Unlike previous operating cycles, where it was observed presence the settled particles of only $5 \mathrm{~cm}$ away from the lower ends of the tubes, the same thing was observed at the upper ends of the tubes, indicating a significant improvement in the flow regime in the tubes especially at the lower and upper ends of the tubes compared to previous operating cycles. Figure 24 shows the spread of particulate matter along the tubes.

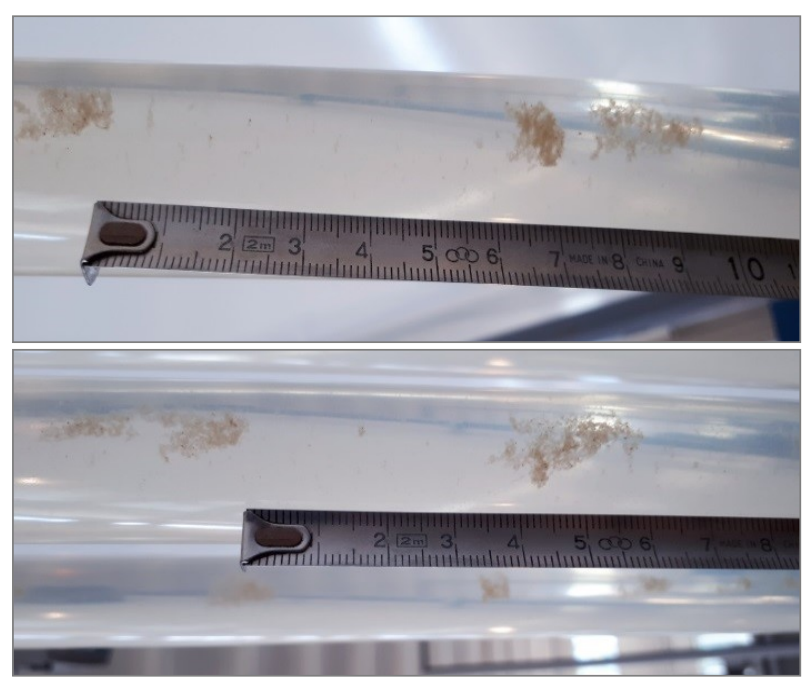

Fig. 23. Masses of the settled particles at the bottom surface of the tube settler. (SLR $0.42 \mathrm{~m} / \mathrm{h}$; inclination angle $54^{\circ}$ ).

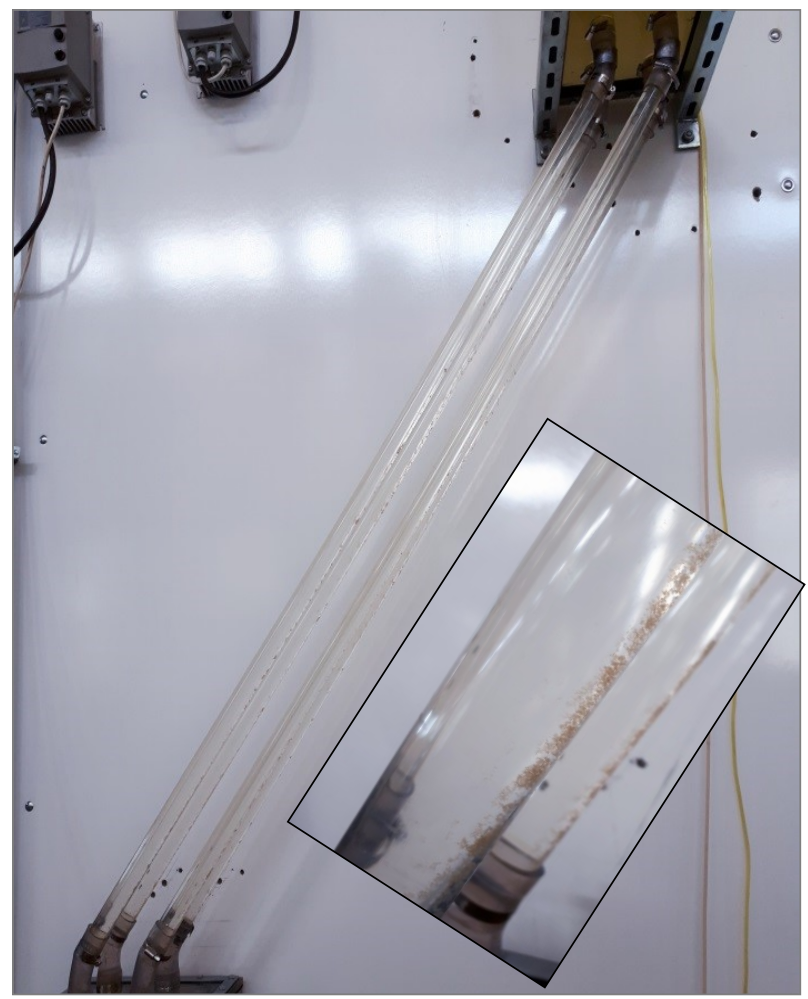

Fig. 24. The Settled particles (Flocs) along bottom Surface of the Tube Settler at (SLR $0.42 \mathrm{~m} / \mathrm{h}$; inclination angle $54^{\circ}$ ).

Sliding small particles on the inner surfaces of the tubes is more difficult than their large-size counterparts because the weight component value of these particles is much less than the shear force. where it was observed that fine particles were stayed over in their place on the bottom surfaces of the tubes even after turning off the Laboratory model for more than 8 hours, this phenomenon was clearly observed when the laboratory model was operated at loading rate of $0.42 \mathrm{~m}^{3} / \mathrm{m}^{2}$.h and 
with the inclination of the tube settler unit at $48^{\circ}$ with the horizontal, which may cause problems in the case of adhesion of these particles at the bottom surface of the tubes. These small and soft particles are spread along the active settling zones of the tubes at the beginning operation of the laboratory model, as well as after it's accumulating and it's sliding towards the sludge collecting basin where the sedimentation cycle of the particles is repeated again and so on.

The smoothness of the internal surfaces of the tubes has an important role in influencing upon the sliding of the settled particles at the bottom surfaces of the tubes and thus largely affects the efficiency of the removal of pollutants. The more smoothness, of the inner surfaces of the tubes, the sliding of the settled particles will be more easily. It was observed during operating the laboratory model at a loading rate of $0.42 \mathrm{~m}^{3} / \mathrm{m}^{2} . h$, that the sliding sludge was not exposed to fragmentation by the force of the water current, as it was observed at the previous operation cycles, especially at a loading rate 2.4 , and $1.8 \mathrm{~m}^{3} / \mathrm{m}^{2}$.h. thus the accumulated sludge was slid down as a single mass under the gravitational forces towards the end of the tube settler unit, but it was exposed to fragmentation when they left the lower ends of the tubes and fallen within the inlet unit as it was observed in the previous operation cycles but with a lesser extent, the main difference here is the inability of the water current to carry those fragmentations and the particles and return them to the tube settler unit. Figure 25, illustrates the sliding sludge on the bottom surface of the tubes at the inclination of the tube unit of $54^{\circ}$ after a period of running the laboratory model with loading rate $0.42 \mathrm{~m}^{3} / \mathrm{m}^{2} . \mathrm{h}$, where the influence of the water currents upon the sliding sludge at the lower zone of the tube was not observed as it was observed when the laboratory model was operated at a flow rate of $1.2 \mathrm{~m}^{3} / \mathrm{m}^{2}$.h (figure 14), which clearly indicates the high improvement of the flow regime at the lower zones of the tubes with a reduction the loading rate.

Also it was observed that reducing the velocity of the coagulated water as it flowing from flocculation basin to the sedimentation basin, reduce the exposure rate of the flocculated particles which were previously formed during the coagulation-flocculation process to breakage and disintegration during their transition between the basins, thus larger percentage of large aggregated Flocs will reach the sedimentation basin, which reflects positively on the settling of those Flocs and upon the efficiency of the removal in general, since that the fragmentation of coagulated particles during its flowing between the basins into smaller and fine particles makes their sedimentation later more difficult. Figure 26, shows the Flocs in the inlet chamber when the laboratory was operated at loading rate of $0.42 \mathrm{~m}^{3} / \mathrm{m}^{2} . \mathrm{h}$, where it can be observed that the formed Flocs during the flocculation process, still retained their pattern and did not fragment apart into small particles, which had contributed to the improvement of the removal mechanism of these Flocs because they have a good bonds between them and thus their settling velocity was a relatively high.

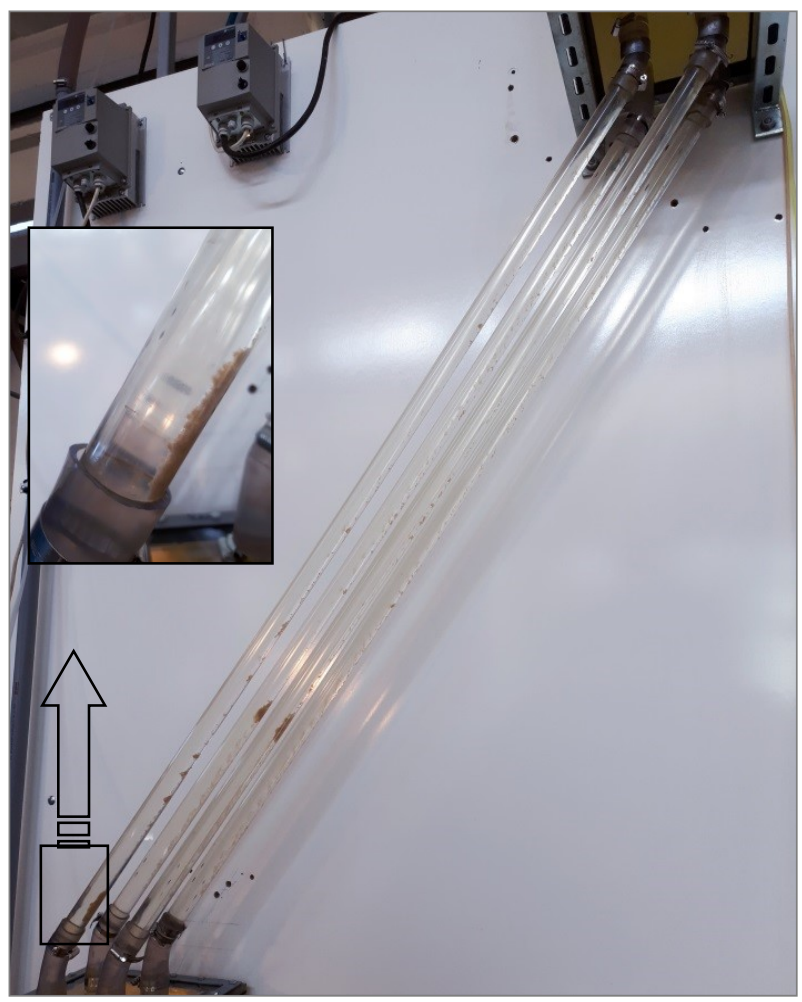

Fig. 25. The Sliding Sludge at the Bottom Surface of the Tube Settler (SLR 0.42m/ h).

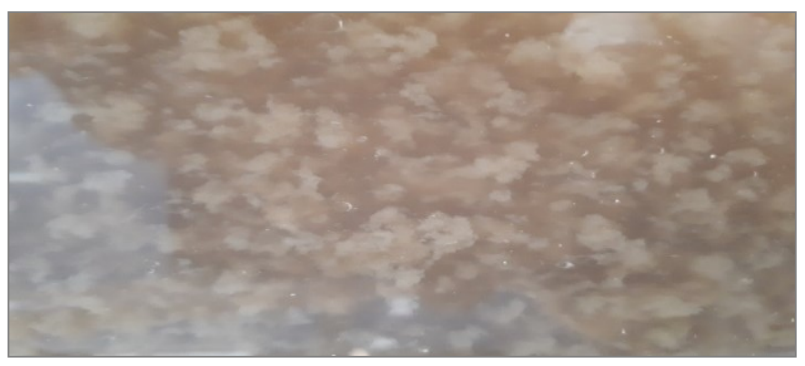

Fig. 26. Flocculated particles (Flocs) within inlet chamber.

\section{Conclusions}

This paper reported the influence of the tube settler at different inclination angles with the change in surface loading rate upon the coagulated industrial effluents. Through the obtained results, we point out the following conclusions:

- Tube settler showed high efficiency in removing coagulated particles.

- Applicability of using tube settler systems as sedimentation units after chemical treatment for the meat industry effluents.

- The results indicated that the effect of changing the surface load rate (SLR) on the removal rates is much bigger than the effect of changing the angle of inclination of the tube settler on the removal rates.

- The length of the sedimentation tubes plays an important role in capturing more suspended particles.

- The tube settler can be divided into effective and ineffective settling zones. 
- The effective settling zones usually occupy the middle section of the tube and associated with the laminar flow regime, while the ineffective settling zones are located in the upper and lower ends of the tubes which usually corresponded to the transition zones.

- The length of the effective settling zone to the total length of the tube depends on the flow pattern within the tubes.

- Significant improvement in the flow pattern was observed as the Reynolds value reduced, in the sedimentation unit, especially in the upper and lower zones of the tubes and in the entrance of those tubes.

- The settled solids (individual particles or accumulated) on the bottom surfaces of the tubes start to slide toward down when the weight component for the solids outperform all forces in the opposite direction (mg $\sin (\theta)>\Sigma$ of the resistance forces).

- The turbulence in the flow within the tubes leads to the re-suspension of the settled particles.

- The sliding sludge is exposed to fragmentation in the zones of disturbance inside the tubes and under tube unit depending on the flow regime in those zones.

- Giving more attention to the design of the inlet units in the sedimentation basins, as well as and to the mechanism of water transmission from the flocculation basin to the basin to the sedimentation basin, will reflect positively the performance of sedimentation basins.

- The velocity of water through the sedimentation unit had a significant effect on the ability of this unit to capture the suspended particles.

- Large-size particles are often settled on the lower and middle sections of effective settling zones within the tubes while smaller particles settle in the middle and upper sections.

- Through the results achieved and observing the behaviour of the sludge during the trials, the inclination angle of $54^{\circ}$ of the tube settler unit showed optimum behaviour, where very good removal rates were achieved with the self-cleaning performance was very satisfactory.

\section{References}

1. P. K. Chhonkar, S.P.Datta, H.C.Joshi, H.Pathak, Impact of industrial effluents on soil health and agriculture Indian experience: Part-II-Tannery and textile industrial effluents, J.Sci.Ind.Res, 59,446454 (2000)

http://nopr.niscair.res.in/bitstream/123456789/26583 1//JSIR\%2059(6)\%20446-454.pdf

2. Ramjeawon, T., Cleaner production in Mauritian cane-sugar factories, Journal of Cleaner Production, 8, 503-510 (2000)

https://doi.org/10.1016/S0959-6526(00)00020-2

3. Kwarciak-Kozlowska, A., J. Bohdziewicz, K. Mielczarek \& A. Krzywicka, The application of $U A S B$ reactor in meat industry wastewater treatment, Civil and Environmental Engineering Reports, 119-128 (2011) http://yadda.icm.edu.pl/yadda/element/bwmeta1.ele ment.baztech-article-BPZ3-0040-

0010; jsessionid=6140812BD0FB6D6C9FF5890121 633296

4. Zueva, S., A. Ostrikov, N. Ilyina, I. De Michelis \& F. Vegliò, Coagulation processes for treatment of wastewater from meat industry, Int. J. Waste Resources, 3 (2013)

https://doi.org/10.4172/2252-5211.1000130

5. Kim, Y.H. (ed.), Coagulants and flocculants: theory and practice (Tall Oaks Publishing, , Littleton, USA, 1995)

6. AWWA. Water quality and treatment. A Handbook of Community Water Supplies (Fifth edition. Raymond D. Letterman (ed.), McGraw-Hill, 1999)

7. Wang, L. K., Y.-T. Hung \& N. K. Shammas. Physicochemical treatment processes (Springer, 2005)

8. U.S Army, Evaluation Criteria guide For water Pollution Prevention, Control, And Abatement Programs, Department of the Army, Technical manual TM-5-814-8.[A technical manual for wastewater pollution control],(1987)

9. Smith, J. E. Upgrading existing or designing new drinking water treatment facilities, Noyes Data Corporation, Library of Congress Catalog Card Number: 90-23205, ISBN: 0.8155.1262.7 (1991)

10. Sarkar, S., D. Kamilya \& B. Mal, Effect of geometric and process variables on the performance of inclined plate settlers in treating aquacultural waste, Water research, 41(5), 993-1000 (2007)

https://doi.org/10.1016/j.watres.2006.12.015

11. Vuković, Ž. Overflow Rate of High Rate Settlers ( Water Pollution 99 The 5th International Conference on Water Pollution Modelling, Measuring and Predicition, 1999)

12. Yunus A. Cengel, and John M. Cimbala, "Fluid Mechanics: Fundamentals and Applications" $\left(4^{\text {th }}\right.$ edition, McGraw- Hill, 2018)

13. Marin Galvin, R., Lamella clarification in floc blanket decanters, a case study, Journal of Water Supply Research and Tecnology-Aqua, 41, 2832(1992)

https://www.researchgate.net/publication/29628626 6_Lamella_clarification in floc blanket_decanters A case study

14. Yu, Y. \& D. L. X. Cui., "Study on Hydraulic Characteristic of the Tube Settler" (International Conference on Mechatronics, Control and Automation Engineering, MCAE 2016)

https://doi.org/10.2991/mcae-16.2016.31 